Dhaka Univ. J. Biol. Sci. 23(1): 85-91, 2014 (January)

\title{
MOLECULAR CHARACTERIZATION OF FOUR MORPHOLOGICAL MUTANTS OF NEUROSPORA CRASSA
}

\author{
Nasrin Akter, Md. Ahashan Habib, Salina Parvin Beauty, Tahsina Rahim \\ and MOHAMmad Nurul ISLAM* \\ Department of Botany, University of Dhaka, Dhaka-1000, Bangladesh
}

Key words: Morphological mutant, Molecular characterization, Neurospora crassa

\begin{abstract}
Four morphological mutants (albino, ropy, conidial band and buff) of Neurospora crassa were characterized based on morphological features and molecular markers. The mycelial color of mutants buff, ropy and conidial band were more or less orange like wild parents. Albino mutant showed colorless mycelium. The germination time of conidia of wild and other mutants ranged from 5 to 7 days while in albino it was 12 days. Esterase and acid phosphatase isozymes analysis of the $N$. crassa mutants clearly indicated that mutation altered the carotenoid biosynthesis pathway creating the albino mutant due to the effect UV light. Most of the mutants viz; albino, conidial band and buff showed characteristic RAPD banding profile. However, no band was found in wild $E m A$, Ema and mutant ropy. Highest number of RAPD bands were found in albino. The mutant albino showed very different morphological and molecular features from the rest specimens.
\end{abstract}

\section{Introduction}

Neurospora crassa is a non-toxic and filamentous fungus belongs to Ascomycetes. It grows in tropical and subtropical regions. It is rich in carotenoids showing bright orange color in the culture. It possesses two opposite mating types called "A" and "a" and has distinct male and female sexual structures ${ }^{(1-2)}$.

Neurospora crassa has been using as a model organism because of its easy growing nature and has a haploid life cycle. The ascospores are linearly arranged that make genetic analysis simple. Wide range of diversity present among the mutants of N. crassa.

A number of molecular investigations and genetics of $N$. crassa have been studied intensively(3-6). In Bangladesh, a good number of classical researches were done on $N$. crassa such as linkage mapping, induction of different morphological mutants by UVirradiation, complementation, segregation pattern, enzyme activities, soluble protein estimation etc. (7-8) However, no molecular research on this materials has yet been initiated which may provide more information about the material.

\footnotetext{
*Author for Correspondence: <mnurul@du.ac.bd>.
} 
To assess the genetic diversity at the molecular level, isozyme techniques with polyacrylamide gel electrophoresis (PAGE) are being used as a powerful tool(9-16). The electrical properties of enzymes in this process can be employed to obtain mobility values for characterization of any organism.

In addition, DNA finger printing by randomly amplified polymorphic DNA (RAPD) is a unique tool for characterizing germplasms authentically. RAPD markers generated by the polymerase chain reaction (PCR), has been widely used since late 1980s of the last century to assess intraspecific genetic variation on a molecular level ${ }^{(17-18)}$.

Therefore, the aim of the present study was to characterize the UV induced mutants by PAGE and RAPD markers and to find the correlation between morphological and molecular data.

\section{Materials and Methods}

Two wild (EmA, Ema) and four induced morphological mutants (albino, ropy, conidial band and buff) of Neurospora crassa were investigated in this study. The wild type strains used in the study were received from Fungal Genetic Stock Centre, Department of Microbiology, University of Kansas Medical School, Kansas, USA. Vogel's minimal medium (VM) ${ }^{(19)}$ was used for the maintenance of cultures.

Five-day-old conidia of Ema were irradiated with UV light having wave length of 254 $\mathrm{nm}$. Radiation was given at a distance of $12 \mathrm{~cm}$. Media supplemented with arginine, histidine, leucine, lysine and tryptophan were used for plating and isolating the irradiated conidia. The isolated conidial cultures were incubated at $25^{\circ} \mathrm{C}$. After 5 days they were observed and classified according to their morphological and nutritional requirements. Fresh conidia of $4-6$ days old cultures of selected morphological mutants and Ema were inoculated at the centre of the VM plate for germination. Germination and radial growth of the conidia were observed under the microscope after 1 and $3 \mathrm{hrs}$ intervals, respectively. Linear growth of morphological mutants and Ema were studied through inoculation of mutant and wild type N. crassa at one end of the Race Tube containing VM media solidified with 3\% agar. Observations were recorded after $6 \mathrm{hrs}$ interval up to $96 \mathrm{hrs}$.

Mycelia were harvested and total genomic DNA was extracted by using CTAB method ${ }^{(20)}$. DNA concentration was quantified through spectrophotometer (Analylikjena, Specord 50, Germany). The A260/280 nm readings for DNA samples were 1.6 - 1.8. The PCR reaction mix for $25 \mu \mathrm{l}$ containing template DNA $(25 \mathrm{ng} / \mu \mathrm{l}) 2 \mu \mathrm{l}$, de-ionized distilled water $18.8 \mu \mathrm{l}$, Taq buffer A 10X (Tris with $\left.15 \mathrm{mM} \mathrm{MgCl}_{2}\right) 2.5 \mu \mathrm{l}$, primer $(10 \mu \mathrm{M}) 1.0 \mu \mathrm{l}$, dNTPs $(2.5 \mathrm{mM}) 0.5 \mu \mathrm{l}$, Taq DNA polymerase $(5 \mathrm{U} / \mu \mathrm{l}) 0.2 \mu \mathrm{l}$. PCR amplification was done in an oil-free thermal cycler (Biometra UNOII, Germany) for 46 cycles after initial denature $94^{\circ} \mathrm{C}$ for $5 \mathrm{~min}$, denature at $94^{\circ} \mathrm{C}$ for $1 \mathrm{~min}$, annealing at $36^{\circ} \mathrm{C}$ for $30 \mathrm{sec}$,

extension at $72^{\circ} \mathrm{C}$ for $3 \mathrm{~min}$ and final extension at $72^{\circ} \mathrm{C}$ for $5 \mathrm{~min}$. Four random primers 
were used for RAPD analysis- viz. Primer-10 (GCC ACG GAG A), Primer-11 (CAC GGC TGC G), Primer 12 (GTA TGG GGC T) and Primer-13 (GCG AAC CTC G).

The amplified products were separated electrophoretically on $1 \%$ agarose gel and DNA bands observed on UV-transilluminator and photographed by a gel documentation system. The PCR products were analyzed after gel electrophoresis. The photographs were critically discussed on the basis of presence (1), absence (0), size of bands and overall polymorphism of bands. The scores obtained using all primers in the RAPD analysis were then pooled for constructing a single data matrix. This was used for estimating polymorphic loci, Nei's gene diversity(21), genetic distance (D) and constructing a UPGMA (Unweighted pair group method of arithmetic means) Dendrogram among the mutants using computer program "POPGENE" (Version 1.31).

Enzyme location on polyacrylamide gel was carried out following standard method with slight modification (22). For this purpose vertical polyacrylamide gel electrophoresis was carried out. Two separate methods of staining were used to detect the enzyme activity on the gels. Before loading, the samples were diluted in the ratio $2: 1$ with the sample buffer. Sample containing $250 \mu \mathrm{g}$ of protein was applied during running of gels. After running, the gels were stained by different methods for two different types of enzyme localization. The incubation mixtures for esterase and acid phosphatase were used in different gels for the detection of two different isozymes. The banded gels were photographed quickly with digital camera.

\section{Results and Discussion}

Four morphological mutants of N. crassa were able to produce from the wild Ema by using a common source and wave length of ultraviolet (UV) ray after exposing to different duration of time. The longest (90S) and shortest (45S) exposer time required in case of mutant buff and albino, respectively. Intermediate exposer time (60S) required for mutants ropy and conidial band (Table 1). This result suggested that duration of exposer time was a factor for developing different mutants.

Table 1. Comparative morphological features of Neurospora crassa.

\begin{tabular}{|c|c|c|c|c|c|}
\hline \multirow[t]{2}{*}{ Features } & \multicolumn{5}{|c|}{ Name of the specimens } \\
\hline & Wild & albino & ropy & conidial band & buff \\
\hline Color of mycelia & Orange & Colorless & Orange & Orange & Buff \\
\hline Structure of mycelia & Wild type & $\begin{array}{c}\text { Mycelia and } \\
\text { conidia cannot be } \\
\text { distinguished }\end{array}$ & $\begin{array}{l}\text { Pink, rope } \\
\text { like }\end{array}$ & $\begin{array}{l}\text { Formed band } \\
\text { at the tip of } \\
\text { the growth }\end{array}$ & $\begin{array}{l}\text { Buff and } \\
\text { fibrous }\end{array}$ \\
\hline Dry weight (g) & 0.8958 & 0.25235 & 0.3141 & 0.73595 & 1.2495 \\
\hline $\begin{array}{l}\text { Conidial germination } \\
\text { (hrs) }\end{array}$ & 6 & 12 & 7 & 6 & 5 \\
\hline
\end{tabular}

The mutants ropy, conidial band and buff were more or less looked like wild in respect of color of mycelia (i.e. orange), conidial germination after inoculation and dry weight 
measured after $72 \mathrm{hrs}$ of inoculation (Fig. 1A, B). However, the albino mutant was totally different from the rest in this regards (Table 1). The orange color of mycelium is due to presence of carotenoid. The mutation in ropy, conidial band and buff did not change the biosynthesis pathway of carotenoid. The lack of orange color in albino clearly indicated that mutation affected somehow in the carotenoid biosynthesis pathway which prevents the synthesis of this pigments resulting the formation of colorless mycelia in albino mutant (Fig. 1A, B).
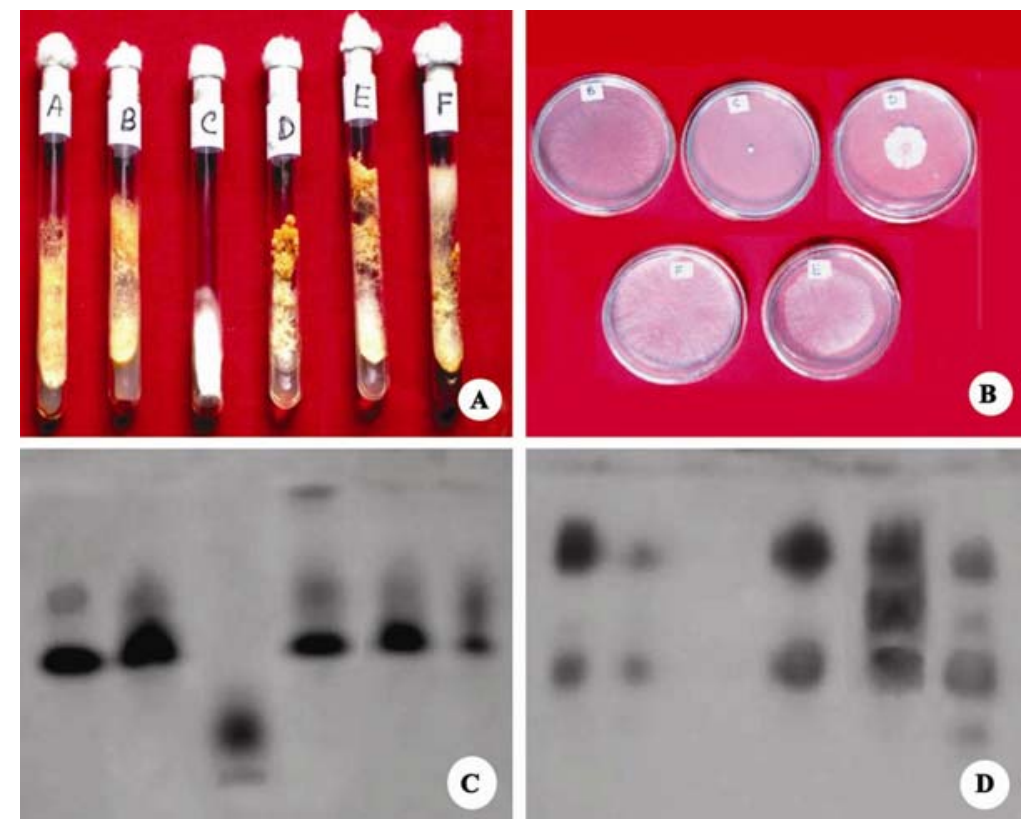

Figs 1A-B. Photograps of wild type and mutants of Neurospora crassa. A. Morphological features. B. Conidial germination and radial growth. C-D. Isozyme analysis of the mycelia extract of Neurospora crassa. C. Esterase activity following Polyacrylamide gel electrophoresis (PAGE). D. Acid phosphatase activity following polyacrylamide gel electrophoresis (PAGE). In all cases, $\mathrm{A}=E m \mathrm{~A}, \mathrm{~B}=E m a, \mathrm{C}=$ albino, $\mathrm{D}=$ ropy, $\mathrm{E}=$ conidial band, $\mathrm{F}=$ buff.

Besides mycelium color, albino mutants were different from the wild and other mutants in two more parameters: (i) time of conidial germination after inoculation was nearly double in albino and (ii) lowest dry weight after $72 \mathrm{hrs}$ of incubation found in albino (Table 1). The delayed germination (Fig. 1B) in albino may be due to change in the DNA responsible for mitotic growth.

Generally mutants are less vigor than the wild since the mutants usually carrying recessive allele ${ }^{(23)}$. In this experiment, an exceptional case was found in buff mutant. The dry weight of the mutant at $72 \mathrm{hrs}$ of incubation was higher than wild (Table 1). The reason for this exception was not clear, however the mutation may change the respective recessive allele somehow. 
The mutant ropy and conidial band differed from wild in respect of conidial structure. The ropy mutant produced rope like conidia while a clear band was formed at the tip of the conidia in conidial band mutants (Table 1). In contrast, the mycelium and conidial structure in albino and buff were like wild. This result revealed that mutation occurred in in the gene responsible for conidial structure ropy and conidial band mutant while, this gene remained unaffected in the mutant albino and buff.

Activities of two isozyme systems viz. esterase and acid phosphatase were investigated in six specimens of Neurospora crassa. In esterase, more or less two common bands were found in all specimens except albino (Fig. 1C). Presence of common bands in five specimens indicated the regular esterase activity. However, albino showed two unique esterase bands at the lower region of the profile (Fig. 1C). This result point out that mutation in albino may change the product of esterase activity into smaller molecular weight thus these two bands found at the lower region of profile. In acid phosphatase, no band was found in albino whereas different banding patterns were observed in the rest five specimens (Fig. 1D) suggested that mutation affected the activity of acid phosphatase in albino.
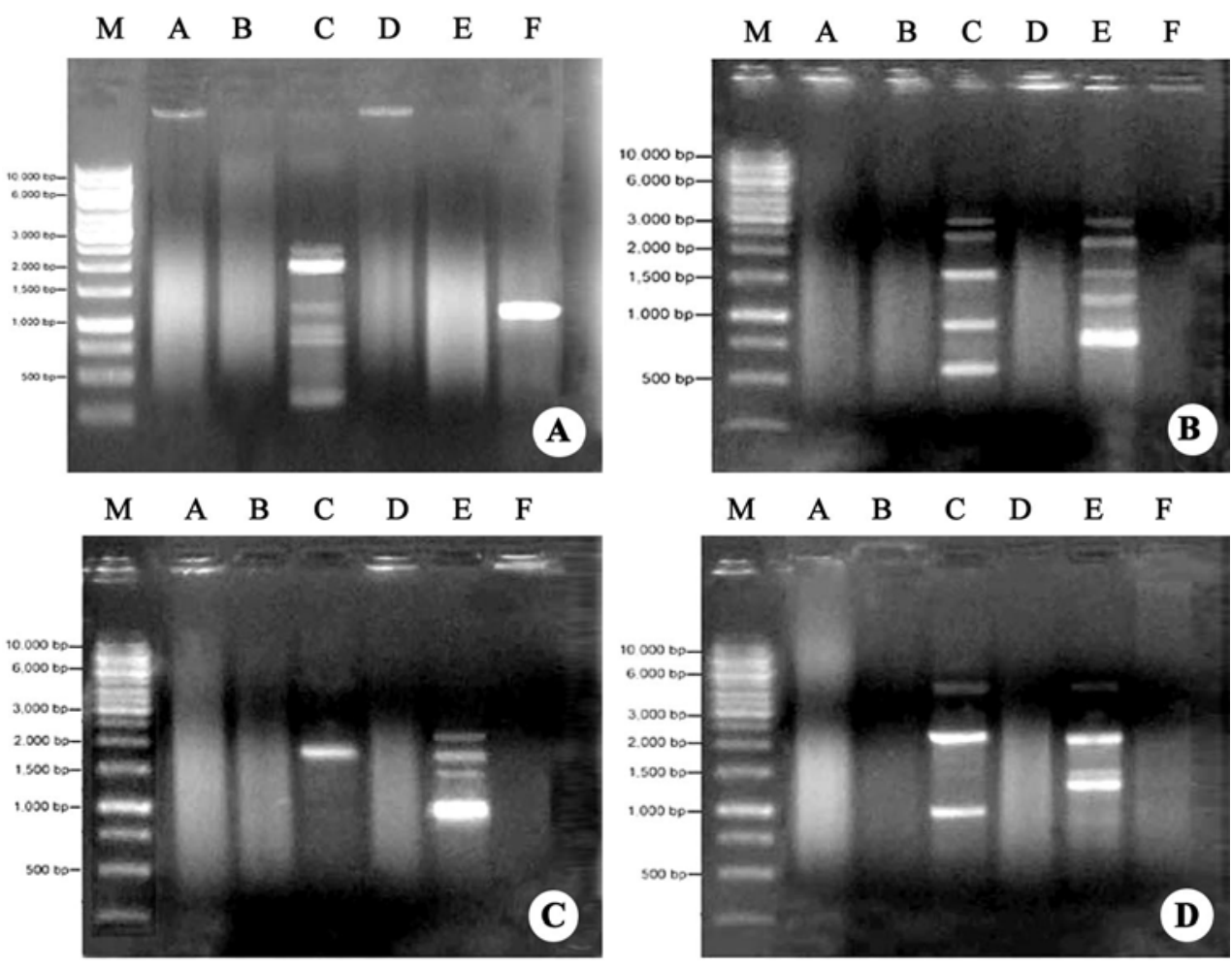

Figs. 2A-D. RAPD analysis: A. Primer sequence GCC ACG GAG A. B. CAC GGC TGC G. C. GTA TGG GGC T. D. GCC ACG GAG A. $\mathrm{M}=1 \mathrm{~Kb}$ DNA ladder, $\mathrm{A}=\mathrm{EmA}, \mathrm{B}=\mathrm{Ema}, \mathrm{C}=$ albino, $\mathrm{D}=$ ropy, $\mathrm{E}=$ conidial band, $\mathrm{F}=$ buff. 
Four primer combinations were used for RAPD analysis of six Neurospora crassa specimens. No RAPD band was found in wild EmA, Ema and mutant ropy. Mutant albino, conidial band and buff showed different RAPD bands. Although these 3 mutants showed some common bands in different primer combinations, each specimen showed characteristic DNA finger printing patterns. Highest number of bands were found in albino for this 4 primer combinations followed by conidial band mutants (Figs 2A-D).

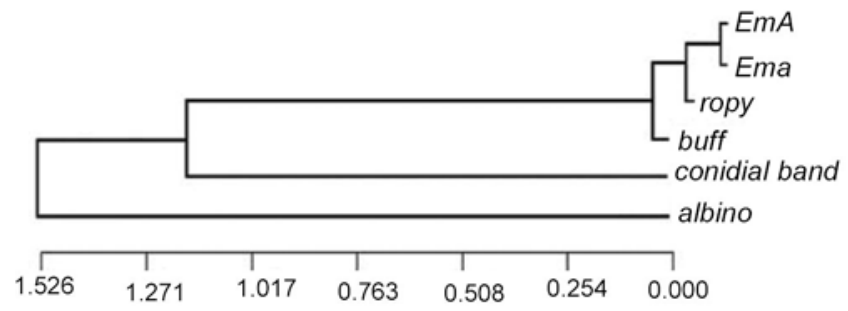

Fig. 3. UPGMA dendrogram based on Nei's genetic distance summarizing the data on differentiation between six specimens of Neurospora crassa, according to RAPD analysis.

With the help of RAPD scoring, a dendogram was made on the basis of genetic distance $^{(21)}$. The cluster analysis clearly indicated that the albino mutant was totally different from the rest five specimens (Fig. 3). On the basis of genetic distance this mutant was separated initially into different clusters. The other five samples however, placed in the same cluster different from that of albino. This differentiation was correlated with the morphological characteristic and isozyme activities. Therefore, a combination of classical and molecular data it was possible to characterize different Neurospora crassa mutants.

\section{References}

1. Glass NL, J Grotelueschen and RL Metzenberg 1990. Neurospora crassa A mating-type region. PNAS 87(13): 4912-4916.

2. Staben C and C Yanofsky 1990. Neurospora crassa a mating-type region. PNAS 87(13): 49174921.

3. Akins RA and AM Lambowitz 1985. General method for cloning Neurospora crassa, nuclear genes by complementation of mutants. Mol. Cell Bio. 5: 2272-2278.

4. Yassin S and A Wheals 1992. Neurospora species in bakeries. J. Appl. Bacteriol. 72: 337-380.

5. Bruchez JJP, J Eberic and VEA Russo 1993. Regulatory sequences involved in the translation of Neurospora crassa mRNA: Kozak sequences and stop codons. Fungal Genet. Newslett. 40: 89-96.

6. Perkins DD and JA Kinsey 1993. New chromosome rearrangements from conidia of Neurospora wild type OR 23-IVA. Fungal Genet. Newslett. 40: 67-68.

7. Haque T and S Shamsi 1997. Activity of some plant extracts on growth of sheath rot pathogen Sarocladium oryzae (Sawada). J. Asiat. Soc. Bangladesh Sci. 231: 153-155. 
8. Mozmader TIMA, N Yesmin and A Jabbar 2000. Induction of mutation in Neurospora crassa with aqueous extract of garlic (Allium sativum L.) and genetic and chromatographic studies of some selected mutants. Dhaka Univ. J. Biol. Sci. 9(2): 143-150.

9. Lowery O, HNJ Rosebrough, AL Farr and RJ Randall 1951. Protein measurement with the Follin-Phenol reagent. J. Biol. Chem. 193: 256-261.

10. Scandalios JG 1974. Isozymes in development and differentiation. Ann. Rev. Plant Physiol. 25: 255-258.

11. Sammour RH 1994. Species relationships in genus Lens as indicated by electrophoresis reappraisal. Lens Newslett. 21: 1-4.

12. Alam SkS, SS Azhar, RH Sarker and MA Zaman 1998. Karyotype analysis with differential banding in Crinum pratense and Crinum defixum. Cytologia 63: 223-227.

13. Alam SkS and N Zarin 1998. Differential fluorescent banding and isozyme assay to distinguish three varieties in Zinnia elegans L. (Compositae). Cytologia 63: 387-393.

14. Alam SkS and SS Deen 2002. Karyotype and isozyme analysis in three forms of Colocasia esculenta (Araceae). Bangladesh J. Bot. 31(2): 95-98.

15. Arüs $\mathrm{P}$ and TJ Orton 1983. Inheritance and linkage relationships of isozyme loci in Brassica oleracea. J. Hered. 74: 405-412.

16. Alam SkS, KN Huda, RH Sarker and MA Zaman 1999. Diversity in C-, fluorescent banding and isoenzyme in Allium cepa. Bangladesh J. Bot. 28 (1): 85-93.

17. Welsh J and MMc Clelland 1990. Fingerprinting genomes using PCR with arbitrary primers. Nucleic Acids Res. 18: 7213-7218.

18. Williams JGK, AR Kubelik, KJ Livak, JA Rafalski and SV Tingey 1990. DNA polymorphisms amplified by arbitrary primers are useful as genetic markers. Nucleic Acids Res. 18: 65316535.

19. Vogel HJ 1956. A convenient growth medium for Neurospora crassa. Microb. Genet. Bull. 13: 42-43.

20. Doyle JJ and JL Doyle 1987. A rapid DNA isolation procedure from small quantities of fresh leaf tissues. Phytochem. Bull. 19: 11-15.

21. Nei M 1972. Genetic distance between populations. Amer. Nat. 106: 283-292.

22. Jonathen F, F wendel and Noman F.Weeden 1990. Visualization and interpretation of plant isozymes. Isozyme in plant Biology (Soltis et al. Eds), pp. 5-45 Springer.

23. Fincham JRS 1954. Effects of a gene mutation in Neurospora crassa relating to glutamic dehydrogenase formation. J. Gen. Microbiol. 11: 236-246. 